\title{
DO ÓDIO À CONVERSAÇÃO: UMA ANÁLISE DOS COMENTÁRIOS DA FANPAGE DO ESTADO DE S. PAULO DURANTE A ELEIÇÃO BRASILEIRA DE 2018
}

\author{
Marina Michelis L. Fernandes ${ }^{1}$ \\ Djiovanni Jonas França Marioto ${ }^{2}$
}

\begin{abstract}
Resumo
A proposta do artigo é verificar quais foram as tendências comuns dos conteúdos expressos nos textos dos comentadores, bem como investigar quais as implicações dessas mensagens nas eleições brasileiras de 2018. Para isso, o banco de dados foi construído a partir da coleta de comentários dentro dos posts na fanpage do Jornal Estado de S. Paulo entre os meses de julho até o dia das eleições do segundo turno, em outubro de 2018, compondo um corpus total de 654.828 comentários. Para este trabalho, calculamos uma amostra estatística com grau de confiança de $95 \%$ e $2 \%$ de margem de erro, resultando em 2.393 comentários. A metodologia empregada é a de análise quantitativa, que foi realizada com auxílio de um livro de códigos. As pesquisas prévias já reconheceram que nas redes sociais os usuários reforçam um tom agressivo e polarizado que circula também fora desse espaço específico. Por conta disso, o trabalho apoia-se em esquemas conceituais que pensam a internet como espaço de conflito, entendendo o pluralismo e o dissenso como categorias fundamentais às análises que tecem as pesquisas sobre política em redes sociais online, sendo esse um caminho para testar empiricamente aquilo que as abordagens teóricas tratam a respeito das potencialidades da rede durante períodos eleitorais. A contribuição, portanto, é pensar as conversas informais geradas na rede como instrumentos passíveis de análise, cujo projeto político não precisa implicar, necessariamente, em uma forma específica de racionalidade.
\end{abstract}

Palavras-Chave: conversação; eleições; redes sociais online; Facebook; internet.

\section{INTRODUÇÃO}

Esse artigo discute como a eleição presidencial brasileira de 2018 foi comentada por cidadãos comuns na página de Facebook do jornal Estado de S. Paulo em matérias de cobertura eleitoral. A novidade que essa disputa presidencial específica possui é o uso cada vez mais intenso das redes sociais como mecanismo de campanha e de engajamento dos eleitores. Isso ficou bastante visível ao se observar a manifestação dos usuários da internet em comentários políticos nos locais discursivos disponibilizados. Embora inicialmente a internet tenha sido idealizada como um espaço oportuno

\footnotetext{
${ }^{1}$ Mestranda em Comunicação pela Universidade Federal do Paraná. E-mail: marinamichelisfernandes@ gmail.com.

${ }^{2}$ Mestrando em Ciência Política pela Universidade Federal do Paraná. E-mail: djiovannimarioto@gmail.com.
} 
para a participação e deliberação de questões comuns entre os cidadãos, atualmente, há trabalhos acadêmicos que demonstram uma experiência um tanto diferente (Brugnago, Chaia, 2015; Aldé, Escobar, Chagas, 2017; Barros, Carreiro, 2015; Ortellado, 2017; Santos, 2014). Com o advento da web 2.0, a campanha digital de Obama em 2008 e a onda de manifestações que se sucederam, a internet passou a ser descrita como uma rede colaborativa e interconectada (Castells, 2009; Jenkins, 2015). Através dessa roupagem esperançosa e otimista em que vestiam-se alguns autores, o futuro do ambiente político e social, diziam eles, assumiria gradativamente novas funções, como a de articular os movimentos sociais pela internet e até possibilidade uma revolução na comunicação política, prometendo novos avanços em uma 'democracia digital' (Gomes, 2005).

Entretanto, como a democracia digital é muitas vezes descaracterizada em seu sentido libertador, foi preciso questionar certos limites nessa investida. Aquilo que prometia oportunidade de trocas e experienciação cívica se revelou, ao longo do tempo, como uma catapulta para a manifestação de comportamentos radicalizados e antidemocráticos (Silveira, 2015). Tomando nota à crítica de Albuquerque (2018) sobre as pesquisas recentes originadas na linha de pesquisa da comunicação política, poucos trabalhos se engajam na investigação crítica do panorama político especificamente brasileiro. Para o autor, além dos veículos de mídia tradicionais, as redes sociais e os websites são também protagonistas dessa crise democrática que temos hoje. Então, mesmo que a internet possa ser uma ferramenta útil para a mobilização civil, conforme já foi observado e comprovado em diversos casos, devemos demarcar um limite entre o que pode ou não ser tolerado nessa participação ativa na rede. Nem sempre todas as pautas são lícitas quando, paradoxalmente, se utiliza da liberdade de voz permitida pelo sistema democrático para reforçar justamente aquilo que viola e desestabiliza as instituições que o constitui como projeto político igualitário. Raciocínio complementar, de Chantall Mouffe (2005), diz que há limites no pluralismo de ideias e nem todas as lutas são legítimas dentro das sociedades democráticas. Nesse caso, certas exclusões são necessárias, mas as razões devem ser encaradas em termos políticos, nunca em termos morais.

Assim, o objetivo deste trabalho é analisar como se estruturam os pontos de tensão entre as conversas dos internautas brasileiros sobre política, principalmente quando havia discordância em relação a algum candidato específico da disputa presidencial. Isso porque em 2018 surge um novo ator político na disputa, que se declara antissistema e vence as eleições, representando um rompimento com a antiga hegemonia partidária tradicionalmente consolidada no histórico eleitoral do país. A ideia, portanto, é entender se a polarização partidária instigou conversas políticas mais 
radicalizadas em torno de nomes específicos da disputa eleitoral. O que parece acontecer, num primeiro momento, é que se aprofunda um clima de conflito entre os participantes das conversas, que se manifestam nesses espaços opinativos, mas sem qualquer interesse em mudá-la, colocá-la em prova ou estruturá-la com argumentos sólidos. Essa demonstração de opinião é muitas vezes intencionada e carregada de tentativas de redução ao outro, injúrias e indiferenças (Figueiredo;Guimarães, 2018).

Demonstraremos que esses comportamentos indesejados dos espaços digitais tomam força notadamente durante as eleições de 2018, devido às significâncias discursivas que adquiriram força nos discursos dos candidatos - mas tais animosidades podem se explicar também por outros contextos. Conforme discutiremos nos próximos capítulos, qualquer tema que seja polêmico pode desencadear violências verbais contra aqueles que apresentam pontos de vista conflitantes (Amossy, 2011). Essa é uma característica naturalmente esperada porque, sendo a conversação um produto social que existia antes do computador, todo comportamento agressivo e polarizado que se observa é, na verdade, algo que já acontecia antes e que talvez são reforçados em virtude de alguns traços próprios das interfaces (Recuero, 2016). Baseada no argumento do filósofo político Carl Schmitt, Mouffe (2005) comenta que a tentativa de eliminação do outro faz parte da separação nós-eles que está presente nas relações antagônicas, cujas diferenças não são respeitadas pelos sujeitos que desejam eliminá-las.

Deste modo, as hipóteses a serem testadas são as seguintes: H1) comentários em apoio a candidatos tendem mais à autojustificação do que necessariamente a proposições estruturadas - são panfletários; H2) Comentários de desaprovação ao candidato tendem a trazer recursos argumentativos de conflitos. Com isso, poderemos exemplificar quais foram as tendências gerais das conversas políticas dos eleitores conectados durante a cobertura eleitoral na página do Facebook de um jornal tradicional no Brasil (Estado de S. Paulo). Durante o desenvolvimento da pesquisa, observamos que boa parte dos comentários que eram publicados nas matérias tinham a função de estabelecer conflitos, objetivando meramente atacar ou desconstruir a imagem do adversário. Os recursos expressivos eram, portanto, emocionais, fazendo prevalecer uma circulação de sensações afetivas, o que nos suscitou a pensar num esquema de análise que permitisse averiguar com mais detalhes esses comportamentos no Facebook. Tal situação foi viabilizada pelo emprego de variáveis de análise quantitativa que se elaboraram com base no viés coloquial que as conversações apresentam, estando a par do aporte teórico deste trabalho. 
Em sintonia com a concepção de democracia elaborada por Chantal Mouffe (2015), consideramos que a discordância e os afetos são elementos centrais na política, bem como nas formas de identificação coletivas, sendo o distanciamento físico do ambiente virtual um dos fatores de catalisação de comportamentos polarizados e radicais (Amossy, 2011). De forma empírica, trabalharemos esse viés especificamente durante a cobertura eleitoral brasileira feita pelo jornal Estado de São Paulo, olhando para a conversação dos seguidores geradas no espaço de comentário das matérias eleitorais dessa fanpage. Trata-se de um tema que vem ganhando espaço nos estudos em comunicação e política, principalmente porque a eleição presidencial de 2018 no Brasil experienciou um investimento intenso de material de campanha via redes sociais. Isso pode ser percebido no uso do Twitter pelos candidatos da disputa, pelas correntes de apoio a votos no whatsapp, comunicação entre representantes e representados no Facebook e até pelo agenciamento político que se intensificou nas redes, tanto no contexto eleitoral quanto em outros assuntos, como por exemplo o tema da maioridade penal, violência de gênero ou formação da bancada evangélica (Cervi, Cavassana, Massuchin, 2018; Sinderski, Cervi, 2019; Reis, Zanetti, Frizzera, 2020; Menezes, 2018).

Diante disso, a metodologia utilizada nesse artigo é a quantitativa, para dar conta do alto volume de dados que se obtém da rede social, mas sem perder no horizonte a natureza do objeto de análise. A ideia é entender o problema em perspectiva dimensional, mensurando numericamente e estatisticamente as informações cabíveis, mas também analisando com certo grau de profundidade esses comportamentos. Para fazer isso, faremos uma amostra composta desses comentários para lêlos com auxílio de um livro de códigos, elaborado com base em um modelo preexistente criado para uma pesquisa maior de que um dos autores faz parte. Adaptou-se novas categorias de acordo com o objetivo desta pesquisa atual.

O artigo segue dividido em cinco partes. A discussão teórica compõe dois capítulos sobre o qual abordaremos o conceito de conversação, sua distinção entre aquela que é realizada face a face e a que se desenvolve no meio online, questões relacionadas ao meio digital e ao uso das redes sociais no caso eleitoral brasileiro. Também, tecemos as principais visadas teóricas que embasaram a análise do material empírico. Já nas seções seguintes traremos a descrição dos procedimentos metodológicos, bem como a apresentação dos resultados metodológicos. Por fim, discutimos os principais avanços dessa investida teórica e metodológica em conjunto com a indicação de possíveis desdobramentos para trabalhos futuros e as considerações finais. 


\section{A ATUAÇÃO DAS CONVERSAÇÕES NA "FACEBOOKZAÇÃO" DA POLÍTICA}

Este segmento objetiva dialogar com as novas abordagens de estudos que tratam das conversações originadas nas redes sociais online. O desígnio é o de ler o quadro de expansão dos usuários ativos na internet, suas manifestações e as implicações destes nesta seara, utilizando-se, para isso, novas abordagens teóricas. Dentre as possibilidades de manifestação de opinião pública, tem destaque o ato de conversar, pois este envolve os sujeitos participantes em um ambiente de caráter informal, incorporando as maneiras pelas quais o cidadão comum conversa sobre o tema político e demais temas sensíveis. Por conta da natureza corriqueira das conversações políticas das redes sociais, estas afastam-se, a priori, dos esquemas normativos que visam a construção consensual da esfera pública (Habermas, 2014).

A nosso ver, não seria possível analisar o conteúdo dos leitores de matérias eleitorais no Facebook apoiando-se em teorias que legitimam a autoridade discursiva pelo caráter racional de interação entre indivíduos. As pesquisas sobre o tema das conversações políticas, sobretudo na comunicação e na ciência política, reforçaram, ao longo da sua trajetória, uma visão idealizada sobre os modos de sociabilidade humana, fornecendo como base para o pensamento político atual categorias como empatia e reciprocidade, mas isso não garante a eliminação de comportamentos "arcaicos" e tampouco uma relação transparente entre indivíduos racionais. Em parte, as pesquisas deliberacionistas se estruturam desta forma porque as tecnologias das quais dispomos hoje se modificam rapidamente, adaptando-se às demandas de seus usuários, o que, por consequência, adiciona complexidade no exercício de tentar descrevê-las na pesquisa científica.

A propósito, uma das maiores questões que temos como pesquisadores é justamente a de acompanhar o ineditismo dos fenômenos que surgem, na medida em que estamos inseridos e fazemos parte, também, desses processos. Obviamente, é preciso lembrar que a predominância de uma abordagem teórica acontece em virtude da própria diferença entre os campos "comunicação e política" e "internet e política", separados por uma década de estudos. Enquanto o primeiro trabalha com veículos já bem estabelecidos, como Rádio, TV e os impressos, a outra acompanha, quase que simultaneamente, a evolução do objeto a que se propõem teorizar (Sampaio, Bragatto, Nicolás, 2016). Porém, ao abordar contextos como o eleitoral nas redes sociais, por exemplo, dificilmente encontraríamos argumentos expressamente racionais, como se almejava inicialmente. A internet é 
marcada por motivações humanas que estão ancoradas por agitações difusas, esparsas e incipientes (Teixeira, 2011).

A sociabilidade humana é ambivalente e não teríamos grandes avanços no pensamento político atual se continuássemos classificando esses comportamentos manifestos na informalidade como algo irracional (Mouffe, 2005). Uma democracia moderna pode ser abordada, também, por outras abordagens que não a racionalista instrumental, porque mesmo que o consenso e a racionalidade sejam desejáveis como meios de atingir algum fim em matéria de política, "isso não nos deveria levar à conclusão de que, na "ausência" de ambos - as aspas importam -, debates como os que acontecem na internet tenham pouca ou nenhuma legitimidade e relevância, precisamente por não conformarem uma esfera pública" (Teixeira, 2011, p.203).

O que se observa na prática, inclusive, são intervenções que caminham em direção oposta ao consenso. Em um estudo sobre os participantes e comentadores dos blogs de política, durante período anterior à febre das redes sociais como o Facebook e o Twitter, Aldé, Escobar e Chagas (2007) identificaram que o ato de emitir opinião nesses espaços se sobressaem ao ato de deliberar. Os internautas se valiam dos comentários para fins meramente expressivos, pouco importando se haveria ali uma construção consensual a respeito dos assuntos sobre os quais comentavam. Os autores seguem afirmando que os blogs se assemelhavam a "botequins" virtuais, cujos temas mais polêmicos como guerra, eleições e escândalos políticos, por exemplo, despertavam o interesse até daqueles que pouco se engajariam nas discussões. Sobre isso, Ruth Amossy (2011) ressalta o potencial da polêmica ao agregar e incorporar cidadãos comuns nas questões políticas. Daí decorre a importância em legitimar os espaços menos institucionalizados como também frutíferos para a constituição democrática. Conforme já descrevia Gabriel Tarde (2005) no final do século XIX, os cafés, os salões e outros espaços de circulação cotidiana, são locais onde se conversa, convertendo-se em verdadeiras "fábricas de poder", pois as atitudes políticas são publicizadas pela mídia e "remastigadas" pela conversação ato esse que é condição para a transformação do poder. É possível supor, deste modo, que nas cenas sociais em que há pouca modificação, as conversas certamente são escassas e tímidas.

Mesmo que sem a pretensão de alterar a ordem da vida política e econômica, a conversação funciona similarmente a um impulso, sendo a potência capaz de movimentar/alterar a vida política: "Politicamente, não são tanto as conversações e discussões parlamentares, e sim as conversações e discussões privadas, que importa considerar. É aí que o poder se elabora, enquanto, nas Câmaras de 
deputados e em seus corredores, o poder se desgasta e, frequentemente, se avilta" (Tarde, 2005, p.121). Para o sociólogo, a imprensa é somente uma das causas da opinião e, sendo a mais recente, estuda-se habitualmente antes. Porém, quando se discorre sobre os elementos formadores da opinião pública e o comportamento das multidões, a conversa é um ato anterior ao surgimento da imprensa que merece também protagonizar os estudos sociais.

Deste modo, a imprensa e a conversação estariam postas, ao longo da história da sociedade, em condição retroalimentadora, haja vista que de nada adiantaria existirem os jornais por si só. Seus discursos não teriam nenhum efeito duradouro nos sujeitos, do mesmo modo que uma conversa sem o alimento da imprensa também se sustentaria com muita dificuldade. Os fatos que acontecem dentro dos espaços institucionais, como parlamentos e câmaras, quando não são publicizados, não têm nenhuma ação sobre os indivíduos. Estas atividades ganham destaque e divulgação justamente pelo potencial que possuem em instigar a conversa e a opinião pública, caso contrário corresponderiam a meros protocolos de poder (Tarde, 2005).

Portanto, é na troca de ideias, no ato de exprimir uma opinião, que os seres humanos conseguem comunicar suas impressões e necessidades. Certamente, os políticos só se popularizam ou são desacreditados na medida em que se conversa sobre suas atuações e propostas de carreira. As conversas estão sempre relacionadas ao mundo real, seus assuntos e suas formas mudam conforme o quadro social em que estão inseridas, variando em qualidade, assunto etc. Nisso, "a conversação se encontra sujeita ou se nutre de várias fontes, constituindo, por isso mesmo, uma espécie-de mediação cotidiana do conjunto das relações sociais, da difusão de ideias e da formação das condutas que têm lugar na sociedade" (Rüdiger, 2011, p.15).

A conversa que se desenrola nas redes sociais é, porém, entre sujeitos diversos, portadores de diferentes realidades sociais e culturais, que muitas vezes não possuem nenhum vínculo, em meio a informações diversas que se difundem em fluxo de tempo extremamente rápido. Num espaço virtual, privamo-nos de algumas noções estéticas que uma conversa entre dois corpos presenciais sustentaria. Postos face a face, os interlocutores agem uns sobre os outros não apenas pela linguagem em si, mas também por olhares, gestos, timbres de voz etc. A despeito dessa conversação que é precursora dos modos de sociabilidade da web, o teórico da opinião Tarde (2005) define-a em função dupla, como fonte e fator invisível da opinião, que flui a todo tempo e em diversos lugares em cursos desiguais, sendo "todo diálogo sem utilidade direta e imediata, em que se fala sobretudo por falar, por prazer, 
por distração, por polidez" (Tarde, 2005, p.75). Em suma, vista como conquista social das civilizações ou, nas palavras do autor, "flor estética das civilizações", a conversação seria uma componente social importante para a propagação de ideias e sentimentos, onde "num domínio geográfico cada vez mais vasto, ela é uma das características mais importantes de nossa época, pois explica em grande parte o poder crescente da opinião contra a tradição e a própria razão" (Tarde, 2005, p.77).

A essa altura, não se pode negar que as conversas, mesmo que atravessadas por contextos corriqueiros, foram historicamente tão importantes quanto as deliberações que acontecem nos espaços mais formais de elaboração de opinião pública. Porém, interessa-nos neste momento entender como ela é manifestada na internet, sabendo que a interação face a face ativa efeitos distintos dos observados via interação virtual. A respeito disso, Rüdiger (2011) defende que as tecnologias exercem um papel relevante no desenvolvimento da comunicação, mas esta função não deve ser superestimada. Embora seja inegável que temos experienciado um momento de expansão dos nossos canais de comunicação, a mediação nem sempre mostra os resultados que idealizamos em uma troca interativa, o que não significa ser necessariamente um problema.

O conflito é constitutivo da política, da linguagem, da comunicação e da sociabilidade em geral. Sendo inevitável, ele só se converte em problema quando assume formas antagônicas de intolerância e inimizade relacionadas à existência do outro. Para Mouffe (2005), no agonismo, o conflito pode ser saudável porque estimula os sujeitos a engajarem-se nas questões comuns. Nisso, vê-se o outro como um adversário respeitável e legítimo. Esta seria, então, uma forma oposta ao consenso, porque toda formação de consenso baseia-se em alguma forma de exclusão. Na democracia radical, as diferenças e a expressão de afetos são constitutivas do agonismo e se sobressaem em relação ao uso público do melhor argumento racional, com finalidade consensual (Mouffe, 2005).

Com base nisso, o que a literatura aponta é que, na verdade, as novas mídias, como o Facebook e outras redes sociais, entrelaçam afetos e ideologias em seus discursos, onde se pode apreender uma tensão entre a busca pela troca e a presença da incivilidade (Figueiredo e Guimarães, 2018). Ao que tudo indica, existe uma compensação psicológica por parte dos participantes na conversação online, que exercem algum tipo de efeito catártico em suas formas de expressão via plataforma online. Esse pode ser um efeito da "sociabilidade conectada" presente no ecossistema tecno cultural comentada por Van Dijck (2016). Os meios técnicos alteram e impactam nossas formas comunicativas, variando 
conforme os contextos e as relações nele estabelecidas. Então, qualquer processo que envolva um meio comunicativo, bem como construções enunciativas, seja verbal ou não verbal, incide diretamente nas relações sociais (Gomes, 2016).

Evocando o termo "miditatização" interpretado por Fausto Neto (2008) como um resultado dos processos midiáticos da sociedade contemporânea, pode-se dizer que as novas tecnologias da comunicação se implicam nas dinâmicas de interação sociais e simbólicas. Avançando mais nesse conceito, o autor fala sobre a passagem da 'sociedade dos meios' para a 'sociedade midiatizada', afirmando que a ideia dos meios de comunicação como elementos organizadores dos processos de interação no campo social é algo já muito debatido, que deve ceder espaço ao fato de que "a constituição e o funcionamento da sociedade - de suas práticas, lógicas e esquemas de codificação estão atravessados e permeados por pressupostos e lógicas do que se denominaria a «cultura da mídia»" (Neto, 2008, p. 92). Há de se reconhecer, atualmente, que a cultura da mídia digital vem convergindo e assumindo o protagonismo no papel de circulação de informação e opinião.

Nesse sentido, o conceito torna-se chave para uma leitura de realidade que não ignore a sistêmica explicativa do processo comunicacional e suas ferramentas. Tal situação, exige, então, "uma mudança de postura por parte do cientista, postura essa que propicie ampliar o foco e entender que o indivíduo não é o único responsável por ser portador de um sintoma, mas, sim, que existem relações que mantêm esse sintoma" (Gomes, 2016, p.15). Isso tem a ver com a pesquisa de Barros e Carneiro (2015) quando dizem que a existência das conversações nas redes sociais não pode ser um fenômeno à parte, uma divisão separada da sociedade, na medida em que interfere nas ações do sistema político. Nesse caso, as formas de interação via Facebook e as redes sociais num geral, podem ser entendidas como resultado de um novo relacionamento mútuo entre processos de socialização e realidades sócio-políticas, potencializando determinadas formas de enunciação e conversação. Essa situação, por sua vez, condiciona e determina tanto nos processos de significação quanto na atuação comunicativa dos dispositivos e seus usuários (Gomes, 2016).

Temos, hoje, uma realidade distinta que, por consequência, também altera as dinâmicas discursivas de nosso tempo. Neto (2008) acredita que a natureza operacional automatizada de nossos meios transforma nossos sistemas tecno-simbólicos em redutores de complexidade. De fato, a conexão e os dispositivos móveis são facilitadores da ligação entre sujeitos geograficamente distantes, da assincronia e da rapidez de circulação dos mais variados conteúdo. Foram traços como 
esses que levaram alguns autores a reforçarem o potencial da web 2.0, sua característica colaborativa e as suas redes interconectadas de seus usuários (Castells, 2009; Jenkins, 2015).Na visão de Lattman e Weltman (2015), propriedades essenciais da atividade humana, como a política e a sociabilidade, vêm surpreendemente se readaptando aos processos de incorporação que a revolução tecnológica em curso impulsiona. Nesse caso, importa o potencial agrupador das redes, envolvendo indivíduos espaçados geograficamente e dispersos em escala demográfica e velocidade, mas chama atenção, sobretudo, a alteração de padrão dessas relações, que adquirem outras potencialidades. E afinal, quais seriam as características dessa alteração/facilitação no potencial comunicativo que o fenômeno de midiatização das redes sociais pode exercer nas conversações?

Não há um consenso (e nem deve haver) sobre os efeitos serem mais ou menos positivos e negativos, pois esses resultados variam conforme os usos desses dispositivos. O que se busca atualmente é observar esse fenômeno e interpretá-lo com o auxílio das elaborações teóricas que estão acessíveis sobre o tema. Os usos políticos e eleitorais das redes sociais, por exemplo, são um fenômeno recente e as suas ferramentas de leitura se alteram gradativamente, tal qual o campo social em que se inserem. Por isso mesmo é importante oportunizar espaço na pesquisa para uma nova sedimentação teórica, manejando outras perspectivas e abordagens que se aproximem das características concretas do objeto. E, para melhor compreender essas modificações, é necessário elucidar o que se toma como referência de manifestação de posicionamento e o que se alterou com a intensificação da conexão em rede.

Dentre as possibilidades ofertadas pelo desenho da plataforma da web, destaca-se a descentralização da produção de conteúdo, a multidirecionalidade e a alta capacidade de interatividade. Estas permitiram que barreiras limitantes como espaço e tempo fossem superadas e dessem lugar a um espaço de engajamento contínuo. Em outras palavras, significa dizer que com a aderência das redes sociais e dos dispositivos tecnológicos móveis, as pessoas podem reagir a qualquer conteúdo produzido, em qualquer momento e lugar, agregando novos significados à informação que ali se consome ou reproduz. Em especial, no Facebook, o engajamento pode ser manifesto em três atos: compartilhar, curtir e comentar; sendo o último tido como o engajamento maior, justamente por demandar mais esforço em relação aos outros (Massuchin, Cervi, 2018). Atualmente, a função de curtir ampliou possibilidades, onde o internauta tem a opção de escolher reagir ao conteúdo com "amei”; "haha" e "ual”. Essa é uma boa representação do que a rede enxerga como estratégico no ato de provocar o engajamento dos seus usuários. Essas reações indicam que o 
Facebook sabe a que quer dar vazão: emoções e afetos. O engajamento, portanto, está nos signos afetivos da plataforma. Um simples de ato de dar like dispensaria, nesse caso, qualquer consideração que seja mais vagarosa.

O estudo de Recuero (2016) afirma que a comunicação mediada por computador é uma maneira de sistematizar certas características da interação face a face e simulá-las na fala. Esses espaços seriam, então, subsequentes das práticas sociais e alteram os sentidos e convenções da conversação. Para a autora, a conversação online seria um tipo semelhante àquele praticado oralmente, mas que é ao mesmo tempo diferente. Ao se observar os padrões de uso das redes sociais, Recuero (2016) descobre que sem a presencialidade síncrona dos integrantes, a falta de contexto tende a tornar-se um grande problema.

Outro fato elencado foi o de que a representação do self, isto é, a representação criada a partir de perfis, poderia também causar um certo distanciamento físico, gerando atos de ameaça, violência discursiva e tentativa de desestabilização do outro, geralmente acionando o humor como recurso. Similarmente, no trabalho de análise do Facebook dos pesquisadores Marques e Guimarães (2018), descreve-se o conteúdo como multidimensional, indo além da mera troca de proferimentos verbais, abarcando metáforas e codificações que influenciam na maneira pela qual as mensagens explícitas farão sentido. Nos comentários, era possível perceber atos de performatividades diversas, disputas por imagens, ódio e constrangimento da expressão alheia. Similarmente, Santos (2014) identificava no cenário brasileiro de 2014 práticas de mobilização de discursos de ódio e intolerância, principalmente partidária. As conclusões de Cleto (2019) são de que no distanciamento físico do suporte virtual há um certo encorajamento a comportamentos de ataque contra "o outro". Para ele, a violência simbólica e física pode ser compreendida como um reflexo das sociedades polarizadas, cujo perfil rejeita qualquer possibilidade de construção consensual.

Ademais, para que se possa compreender as relações entre o Facebook, os comportamentos apontados pela literatura e as questões políticas, é preciso discorrer sobre as singularidades do ambiente eleitoral brasileiro de 2018.Na próxima seção, apresentamos com mais detalhes a concepção de "político" elaborada por Mouffe (2015) para explicar as características dissensuais dos comentários publicados em matérias de cobertura eleitoral durante o recorte da pesquisa. As pesquisas prévias levantadas reconhecem que as identidades agenciadas pelas redes sociais reforçam o tom agressivo e polarizado que circula também fora desse espaço específico. Isso porque existem 
características próprias de mediação das ferramentas digitais que catapultam certos tipos de comportamentos indesejáveis na política democrática. Acreditamos, dessa forma, que as narrativas antidemocráticas e os comportamentos agressivos que demarcam o ambiente de conversação durante o período eleitoral solicitam novos encaminhamentos que deem conta desta tônica.

\section{O ANTAGONISMO E POLARIZAÇÃo POLÍtica NO CONTEXTO ELEITORAL BRASILEIRO}

Conforme vimos anteriormente, na internet as pessoas procuram a auto afirmação e depreciação do ponto de vista divergente, inviabilizando que as conversas das redes sociais online se adequem ao padrão ideal normativo de cidadãos engajados politicamente. Mostramos também que foi preciso questionar o sentido libertador e progressista da internet, já que "a rede benefíciou em um primeiro momento a diversidade de perspectivas, inclusive aquelas contrárias à democracia e à liberdade (Silveira, 2015, p. 215). Portanto, as conversas informais entre os sujeitos dentro do espaço da internet formaram palco para superficialidades e demonstração de comportamentos agressivos, fenômeno bastante distante da normativa deliberacionista.

O choque de opinião é natural e esperado dentro da linguagem humana, mas em certos momentos se aguçam as visões que são contraditórias até torná-las inconciliáveis, na dicotomização (Amossy, 2011). A grande questão é que a dicotomização não desencadeia somente bolhas de grupos identitários, mas também trabalha para que os grupos se afirmem através da destruição da imagem do outro (Amossy, 2017). Os efeitos disso são observados na violência verbal e nos discursos marcados pela phatos: "Não nos impressiona, portanto, ver que a exacerbação de oposições se concretiza, in loco, numa divisão em grupos antagônicos, em que cada um afirma sua identidade social opondo-se e fazendo do outro o símbolo do erro e do mal” (Amossy, 2017, p.58). A despeito disso, Mouffe (2015) explica que as identidades políticas se constituem dentro de um tipo relação “nós/eles", a qual deve ser compatível com a aceitação do pluralismo na democracia política.

A distinção entre amigo/inimigo que indesejavelmente pode emergir das relações sociais configura o que Mouffe (2005) nomeia por antagonismo: "Isso acontece quando se acredita que o ‘eles' está questionando a identidade do 'nós' e ameaçando sua existência” (Mouffe, 2005, p.15). Essa situação se explica porque há uma ausência de mecanismos que funcionem como "válvula de escape democráticas" para as paixões e os afetos, atravancando a dinâmica pluralista, o que por consequência transforma o outro da condição de adversário para a condição de um inimigo, que deve 
ser eliminado. Na prática, observa-se que as formas essencialistas de identificação e valores morais rígidos tomam o lugar do confronto no projeto de democracia agonística (Mouffe, 2005).

Para aprofundar o tema, passamos brevemente pelo regime de semióticas mistas, onde Deleuze e Guatarri (2011) criticam que é preciso se desfazer dos falsos problemas colocados pela linguística para entender que, em sua origem, toda linguagem faz parte de um agenciamento coletivo de enunciação, onde seus usos são fundados e fundantes no agenciamento de corpos, ações e afetos. Haveria, portanto, uma soldagem concreta entre elementos que são arbitrários em nossa sociedade comunicativa. Por conta disso, os autores sugerem o uso de uma pragmática da linguagem, definida também como uma política da língua que permite aferir sobre a realidade de certos agenciamentos de poder em nossa sociedade. Estes agenciamentos não se dão exclusivamente na língua, e sim se constituem como forças que são implícitas e pré-dadas (arbitrárias).

A linguagem, por sua vez, não é exclusivamente informativa e comunicativa, mas, principalmente, constitutiva e constituída pelas relações materiais que temos, por nossos usos efetivos. Em outras palavras, linguagem seria um funcionamento social, enquanto falar seria um ato de mobilizar materialmente o mundo. Essa realidade mundana é subjacente à própria linguagem, onde coexistem forças de territorialização e desterritorialização no campo social. Territorialidade seriam os dispositivos de poder, como o Estado, a religião e a moralidade, por exemplo. A desterritorialidade seria aquilo que os autores definem como movimentos de liberação, de fuga dessas territorialidades. Paradoxalmente, as identidades surgiriam, então, como um desejo de identificação no campo social por parte do sujeito, um retorno a uma reterritorialização.

As formas essencialistas de identificação citadas por Mouffe (2005) poderiam representar, nesse caso, uma dificuldade do projeto democrático atual em conciliar essas relações marcadas pelo fluxo de trocas de territorialização e desterritorialização que integram o campo afetivo social. O que se pode notar atualmente é que existem formações identitárias essencialistas e outras que formam uma contra-cultura, todas em busca de uma hegemonia coletiva de enunciação, entrelaçando desejos, corpos e afetos. Se nossos conceitos, visões e opiniões circulam por meio de suportes materiais, então há, de fato, um horizonte político da linguagem que pode ser observado na definição material de poder, que busca ligar as palavras à certas coisas. Também, se hoje temos uma divisão política entre a formação identitária de um "nós" contra a ameaça de um "eles”, é porque certas subjetivações se 
dão como uma tentativa de proteger-se daqueles que buscam fugir dos elementos moralizantes da política.

Nas redes sociais isso fica claro quando estudamos o modo pelo qual as pessoas usam a linguagem efetivamente, ou então em como essa linguagem se atualiza no ato de enunciar nesse espaço digital. Conforme veremos adiante, na discussão dos resultados, os espaços discursivos da internet no Brasil pareceram funcionar como ferramentas de catarse emocional, performance discursiva e auto-afirmações. Por isso, um dos maiores desafios da política atual seria justamente o de superar a idealização do consenso racional e a eliminação das diferenças, buscando, ao contrário, propiciar novos canais para o estabelecimento dessas diferenças, num exercício de permitir que certos fluxos afetivos se liberem, sem por isso recorrer a uma moralização da política como forma de proteção identitária.

Ademais, na eleição presidencial brasileira de 2018, vimos a ascensão de uma nova figura política da ultra-direita conservadora, com forte apelo popular, influenciando na construção de uma identidade anti-sistema e moralista por meio de pautas eleitorais polêmicas. A adesão popular ao candidato Jair Messias Bolsonaro foi elucidativa no sentido de haver rompido com uma polarização que era historicamente definida nas disputas eleitorais brasileiras, entre o Partido dos Trabalhadores (PT) e o Partido da Social-Democracia Brasileira (PSDB).

Além disso, outro ponto de destaque para 2018 é que, diferentemente do que assistimos nas eleições anteriores, desponta-se uma cultura política digital fortemente demarcada pela crise das instituições tradicionais, na qual o Facebook torna-se uma das principais fontes de informação política dos agentes mobilizadores (Ortellado, 2017). Na análise de caráter conjuntural realizada por Cleto e Corrêa (2019), vê-se que as manifestações de 2013 reuniram uma pluralidade de reivindicações associadas ao transporte urbano, que vieram a se desdobrar em múltiplas pautas, atacando o complexo político em sua integridade. Esse foi o momento em que uma crise de representatividade política passou a ganhar força, contribuindo para a ascensão de uma nova direita no Brasil.

A desconfiança não dizia respeito somente aos partidos e figuras políticas, mas, de forma generalizada, estava voltada para os meios de controle e fiscalização democrática, como os jornais, por exemplo. A mobilidade dos aparelhos celulares e a recirculação possibilitada pelo Facebook foram elementos importantes nesse novo estilo de comunicação e mobilização política que alteraram 
profundamente o cenário eleitoral brasileiro, onde "fica claro que a cobertura da manifestação não era mais uma exclusividade da velha imprensa. Os protagonistas das ruas usavam as redes sociais para postarem sua versão e sua visão dos acontecimentos” (Silveira, 2015, p. 218).

A maior aderência dos usuários das redes sociais pode ser explicada pelo estudo de Ortellado (2017), que demonstra que o uso da internet e, particularmente, do Facebook, reduziu o tempo que era destinado ao consumo de outros produtos editoriais e jornalístico. Deste modo, estimularam-se novos processos de interação e de conversação que se deram no espaço online. Para Cleto (2019), é indissociável a relação entre a elegibilidade de Bolsonaro e as redes sociais, principalmente porque, diferente do protocolo comum eleitoral que esteve tradicionalmente centrado no Horário de Propaganda Gratuita Eleitoral (HGPE), o candidato teve pouco tempo na televisão, restando apenas a internet como alternativa. Porém, em nível mais meticuloso de observação, "as redes sociais desempenharam papel central não apenas durante o processo eleitoral como também na construção de um novo modelo de debate público e da própria figura do "mito" - apelido que ganhou o capitão quando viralizaram as primeiras publicações a seu favor" (Cleto, 2019, p.4).

O deslocamento da atenção para as plataformas de redes sociais como o Facebook gerou a formação de nichos e grupos de interesses que, além de possibilitarem acompanhar os acontecimentos de maneira instantânea, algo que no espaço tradicional de comunicação não é possível, eles ainda “instigaram uma sensação inédita de pertencimento que nem sem sempre se limita ao universo digital, formando novas identidades, polarizadas e engajadas" (Cleto, 2019, p.3). Disso, podemos compreender o universo das redes sociais online como um ambiente de conversação que facilita a circulação de opiniões opostas e, consequentemente, na formação de nichos polarizados de posição política. Com a crescente influência das redes sociais nos processos eleitorais, é importante compreender como isso se deu nas eleições do Brasil em 2018. Para tanto, apresentamos na sequência os detalhes do procedimento metodológico e seus principais resultados como investigação teóricametodológica.

\section{Metodologia}

A fase empírica da pesquisa se realizou a partir da análise de conteúdo quantitativa (Bauer, 2007) dos comentários postados em matérias de cobertura eleitoral no jornal Estado de S. Paulo 
durante a disputa presidencial de 2018. O banco de dados foi construído a partir da coleta de comentários dentro dos posts da fanpage do Jornal Estado de S. Paulo, durante o período eleitoral, entre os meses de julho e outubro de 2018, compondo um total de 654.828 comentários. Para isso, foi criado um web scraping em linguagem Python para se comunicar com a API da plataforma e coletar as informações solicitadas. Após uma primeira análise sobre o banco de dados, foram selecionados apenas os posts que tratavam das eleições brasileiras daquele ano, reduzindo para 439.223 comentários. Essa clivagem foi escolhida porque dentro do banco de dados inicial havia posts e comentários que nada tratavam sobre política e eleições.

Para analisar o banco de dados, compomos uma amostra de 384 comentários $^{3}$ aleatórios gerada a partir do banco completo. Desse modo, a codificação numérica dos elementos textuais dos comentários se deu a partir do livro de códigos, o qual foi redigido com vistas a guiar a análise das conversações que se inscrevem nos espaços de comentários disponibilizado por redes sociais online. Tal análise de conteúdo vai ao encontro das especificidades das plataformas, considerando o distanciamento físico do ambiente virtual como fator catalisador de comportamentos polarizados, agressivos e com caráter afetivo. As variáveis aqui propostas, portanto, buscam categorizar as conversações pelo viés coloquial que as caracterizam. Para tanto, mantemos no horizonte a concepção de democracia elaborada por Chantal Mouffe (2015), na qual a discordância e os afetos são considerados elementos centrais na política, bem como nas formas de identificação coletivas.

A variáveis que compõe o livro de códigos foram as seguintes: posição em relação ao candidato, tipo de pensamento, estruturação do comentário, formulação/forma do problema, recursos de expressão na linguagem/afetividade, recursos argumentativos de conflito, recursos argumentativos de construção, fonte e estratégia persuasiva dominante. A variável posição em relação ao candidato era classificada se comentário fazia menção, aprovando ou desaprovando, a algum candidato da disputa. A ideia era verificar como as preferências eleitorais eram manifestas pelos comentadores de acordo com cada candidato.

Já a variável tipo de pensamento dividia-se em três: social, quando os comentários enunciavam situações da sociabilidade num geral, como boas-vindas, apresentação pessoal, pedidos de desculpa etc.; meta-conversação, quando referiam-se à própria conversação, tratando da estrutura

\footnotetext{
${ }^{3}$ Além da escolha aleatória dos comentários, ela foi produzida a partir de $95 \%$ de grau de confiança e $5 \%$ de margem de erro do banco de dados completo.
} 
da fala ou tendo como foco os indivíduos envolvidos na conversa, mas não a temática em si; e problema, quando os comentários focam no tema (eleições), apresentando opiniões, fatos, questionamentos acerca do tópico.

A variável estruturação do comentário se aplicava de duas maneiras: panfletária, quando o comentador se restringia apenas ao tema eleitoral, servindo como um "panfleto" para determinado candidato, ou estruturada, quando apelava para questões externas à discussão central, adicionando novas informações à conversação. A variável formulação/forma do problema representava como o leitor se colocava estrategicamente perante os outros comentadores, podendo ser uma oposição tolerante, estabelecedora de conflitos ou de concordância.

A variável de recursos de expressão na linguagem foi dividida entre "noção de hipérbole", contendo exagero propositado na expressão linguística, "performance/performatividade" trazendo a ideia de desempenho pela linguagem e ação performativa, "efeito de catarse”, estando relacionado a uma descarga emocional que parece exceder um discurso racional e equilibrado, e "sentimento de pertencimento", que ocorria quando o comentador expressava noção de identificação, reconhecimento ou pertencimento coletivo em relação a algum grupo/movimento/candidato; Os recursos argumentativos de conflito eram compostos por ações e comportamentos de conflito, comumente utilizados pelos comentadores como "ameaça", "sarcasmo" e "insulto". Enquanto os recursos argumentativos de construção eram divididos em dois códigos: "analogia" e "narração argumentativa".

As fontes eram divididas em sete, podendo ser de origem "pessoal”, "mídia tradicional”, "canais alternativos", "religiosa", "científica", "doxa"4 ou uma "opinião contrafática"5. Por fim, a estratégia persuasiva dominante era uma variável relacionada à disposição conversacional, tendo como foco a maneira pela qual se reforçam os pressupostos. Desse modo, elas podem ser: "Retórica propositiva/apelo pragmático", "Retórica sedutora ou ameaçadora/apelo emocional”, "Retórica éticomoral/apelo ideológico", "Retórica crítica/apelo à credibilidade da fonte".

\section{Resultados}

\footnotetext{
4 opinião do senso comum ou mera opinião. Impressão pessoal. Conhecimento infundado. Pode ser tanto verdadeiro quanto falso, pois não foi submetido ao teste

${ }^{5}$ Não é uma opinião pessoal, nem se encaixa na categoria doxa (senso comum não verificado). Desafia abertamente uma posição cientificamente provada
} 
Inicialmente, optamos por apresentar descritivamente as frequências simples dos comentários. Depois, passaremos aos cruzamentos entre variáveis relevantes. Deste modo, a primeira frequência é sobre a variável de menção (aprovação/desaprovação de candidatos). Quando observamos a posição dos comentários em relação aos candidatos, encontramos uma maioria que declarava apoio, com $48,7 \%$, seguido pelos comentários que não traziam posição ou menção a candidatos em 43,2\% dos casos, e, apenas $8,1 \%$ dos comentários apresentaram desaprovação.

No que diz respeito à relação de estruturação dos comentários, encontramos uma predominância do tipo panfletário sobre o estruturado, 60,4\% e 39,6\% respectivamente. Isso significa que os comentários deixavam ideias soltas e pouco estruturadas sobre o tema eleitoral, recorrendo, em muitos casos, a acontecimentos políticos externos à disputa eleitoral, mas que tinham efeitos políticos, como por exemplo o caso de Marielle Franco ou a prisão do ex presidente Lula. Poucas foram as conversas que traziam uma opinião elaborada sobre o tema eleitoral, o que nos indica também que houve pouco esclarecimento dos comentadores a respeito de seus pressupostos.

Passando para as variáveis de tipo de pensamento, encontra-se uma baixa presença do tipo social, ocorrendo em apenas 2,3\% dos casos, demonstrando pouca interação entre os comentadores, e a baixa utilização de saudações ou interações que demonstra uma maior troca e diálogo entre eles, ao passo que a meta-conversação já ocorria em $72,1 \%$ dos comentários, o que pode significar uma preocupação com a linguagem e com a forma do que se era escrito e publicado. Já a variável do tipo problema apareceu em 42,4\%, demonstrando uma certa centralidade de comentários que estavam focados no tema central da eleição, não fugindo do tema enquadrado pela matéria jornalística. Quando se observa a formulação do problema, os comentários estão concentrados no estabelecimento de conflitos, com $45,4 \%$, seguidos para os comentários que estabelecem uma oposição tolerante $(31,1 \%)$ e, por último, em 23,5\% dos casos, buscavam estabelecer uma concordância. Isso mostra que, em acordo com o aporte teórico, as conversas no Facebook apelavam para um acirramento de ânimos. Nisso, o objetivo era meramente atacar os desconstruir a imagem do adversário. Os comentários que demonstravam consonância entre os comentadores foram estatisticamente raros dentro dessa amostragem, provando que boa parte das conversas foram registradas para demarcar posição de diferenciação perante o conteúdo exposto.

Os recursos de expressão na linguagem ou afetividade demonstraram uma predominância de comentários que destacam uma performance ou uma performatividade dentro do contexto eleitoral 
(51,2\%), sendo seguido pelos códigos "efeito de catarse", "sentimento de pertencimento" e "hipérbole" que apareceram 19,2\%,16\% e 13,6\% respectivamente. Aqui, a intenção era descobrir quais eram os recursos especificamente afetivos utilizados nas conversações e como estes eram enunciados. Com isso, teríamos pistas dos efeitos emocionais da linguagem acionada pelos comentários. O resultado nos mostrou que a intencionalidade era predominantemente centrada no desempenho pela linguagem, ou seja, os sujeitos falavam com intuito de gerar um efeito no outro que lê. Também teve destaque a catarse, representando uma descarga emocional que parecia se exceder na hiper expressividade afetiva. Estes eram associados a desabafos pessoais ou ataques ofensivos direcionados a alguém, estando também ligados a uma sensação estética.

Com a variável 'recurso argumentativo de conflito' nosso objetivo era identificar sob que formas o conflito se estabelecia nas ações e comportamentos dos comentadores. Esta categoria ocorreu apenas na metade da amostra, e foi dividida entre o sarcasmo e o insulto, cada um com 46,4\% e 43,2\% respectivamente, enquanto a comentários que continham qualquer tipo de ameaça ocorreram apenas em 10,4\% dos casos. Por outro lado, os 'recursos argumentativos de construção' foram pensados para auxiliar na visualização comparativa em relação ao conflito. Estes apareceram em pouco mais da metade da amostra $(59,6 \%)$ e tiveram o predomínio da analogia em relação a narração argumentativa, $57,6 \%$ e $42,4 \%$ respectivamente. As porcentagens nos mostraram que ambos se distribuem de maneira equilibrada no corpus, lembrando que construção dizia respeito a como a opinião era construída, podendo ser didática/explicativa ou apelando para uma narrativa de história pessoal.

Passando para as fontes utilizadas na justificação e construção dos argumentos, a mais utilizada foi a "Doxa" (45,3\%), a qual é composta por argumentos do senso comum, seguida pela fonte "pessoal" $(29,8 \%)$ e a mídia tradicional $(10,7 \%)$, todos os outros códigos tiveram menos de $10 \%$ de ocorrência. Esses dados demonstram uma centralidade dos argumentos em percepções do comentador, tanto de sua vida pessoal como também de construções que ocorrem no dia a dia que é o caso da "doxa".

Por fim, a última variável que foi codificada é a 'estratégia persuasiva dominante'. Grande parte dos comentários utilizaram a estratégia sedutora ou ameaçadora com apelo emocional (46,1\%), seguida por uma retórica propositiva com apelo pragmático (24\%) e um retórica crítica com um apelo à credibilidade da fonte $(21,9 \%)$. Por outro lado, quase não foi utilizada a retórica ético-moral com 
apelo ideológico. demonstrando que o os comentários buscavam mais impactar a partir da emoção do que explorando pontos mais críticos ou pragmáticos.

Quando cruzamos o posicionamento em relação aos candidatos (aprovação/desaprovação) com a estruturação dos comentários, o resultado foi que os comentários que declaram apoio, em sua maioria, são comentários panfletários, trazendo uma baixa estruturação ou justificativa. Ademais, descobrimos que os comentários estruturados não possuem relação a algum candidato explícito dentro dos comentários, como pode ser observado no Gráfico $1^{6}$. De acordo com a nossa hipótese, os comentários em apoio a candidatos tendem mais à autojustificação do que necessariamente a proposições estruturadas. Portanto, estávamos corretos quanto a essa sugestão. De fato, os comentadores utilizavam os espaços de conversação como ferramentas de auto-justificação ou declaração de voto. Havia pouca intencionalidade em construir debates críticos ou até mesmo de conversar com os outros participantes. Isso nos indica, conforme aponta a discussão teórica, de que os conversadores entram nestes espaços com pressupostos já definidos, pouco importando-se com a justificação de suas posições. As declarações panfletárias demonstraram, desta forma, que o engajamento era puramente performativo, com intenção de afirmar uma posição individual.

\footnotetext{
${ }^{6}$ O cruzamento entre as variáveis deste gráfico possuem associação estatística significativa, com qui quadrado de 42,456 e sig , $000 *$
} 
Gráfico 1 - Cruzamento entre a posição em relação ao candidato e a estruturação do comentário.

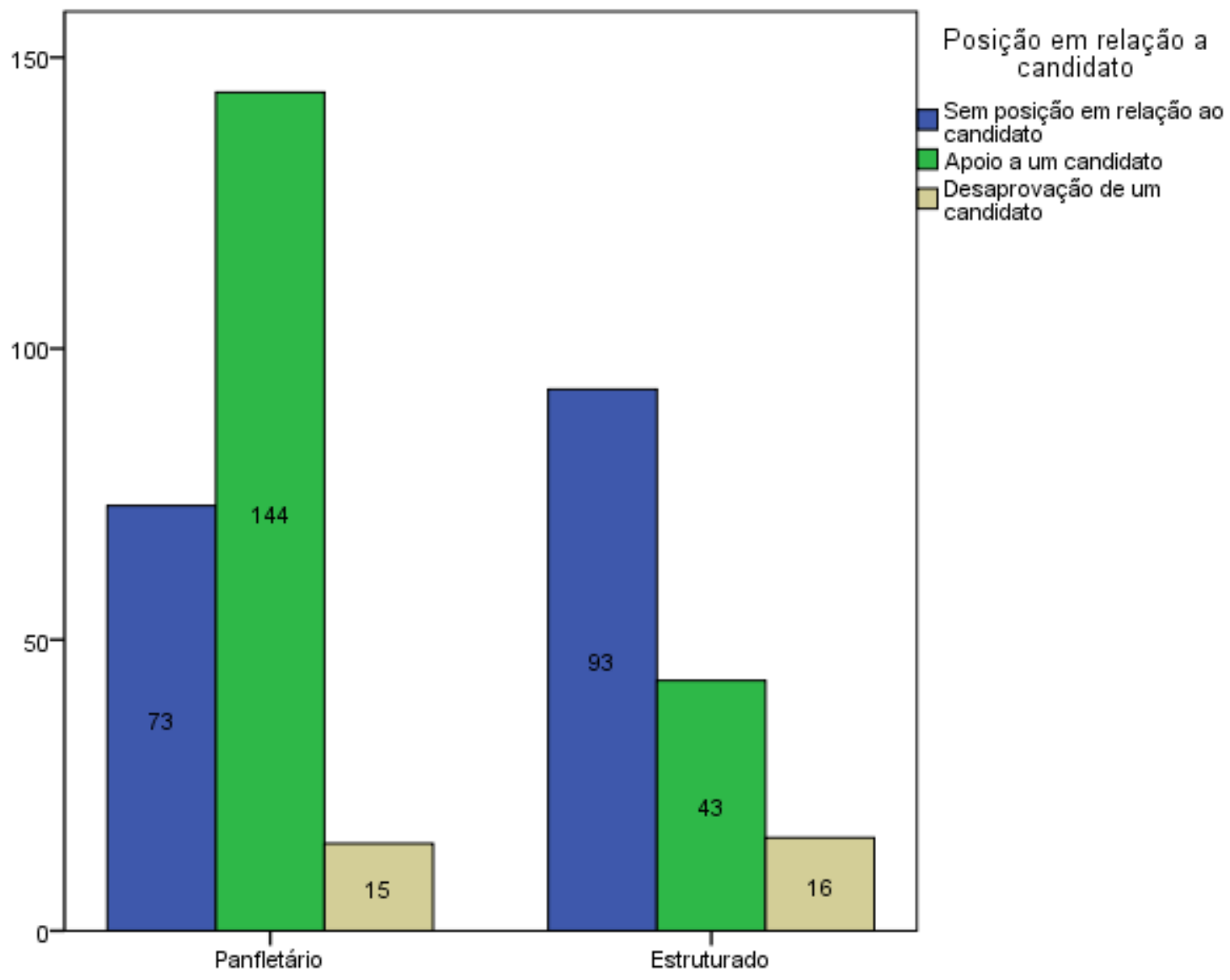

\section{Estruturação de comentário}

Fonte: Autores

Ao fazer o cruzamento dos recursos argumentativos de conflito com a posição em relação aos candidatos, encontrou-se uma predominância de comentários que não possuíam uma posição ou um candidato definido quando se utilizava sarcasmo ou insulto. Mesmo com a baixa ocorrência, a ameaça apareceu mais quando havia apoio a um determinado candidato. O que explica essa invertida na situação é que a eleição presidencial de 2018 no Brasil foi marcada pela disputa política e ideológica entre os candidatos do PT e PSL, onde ambos os partidos assumiram posicionamentos políticos explicitamente polarizados. Nesse caso, os eleitores de Bolsonaro, ao mesmo tempo em que manifestavam apoio ao candidato, traziam elementos de ameaça em seus comentários. Ao passo que simpatizantes do PT utilizavam da mesma estratégia, também marcando posição conflitante. Como marcamos a opção que 
predominava no comentário, o problema que nos deparamos foi de que havia, ao mesmo tempo, a exaltação de um candidato específico e a destruição da imagem dos eleitores do outro. Portanto, o que foi encontrado, no Gráfico 2, coloca em xeque a H2 deste trabalho, já que não houve uma maior ocorrência de sarcasmo, ameaça ou insulto em comentários que desaprovava um determinado candidato

Gráfico 2 - Cruzamento entre a posição em relação ao candidato e o recurso argumentativo de conflito.

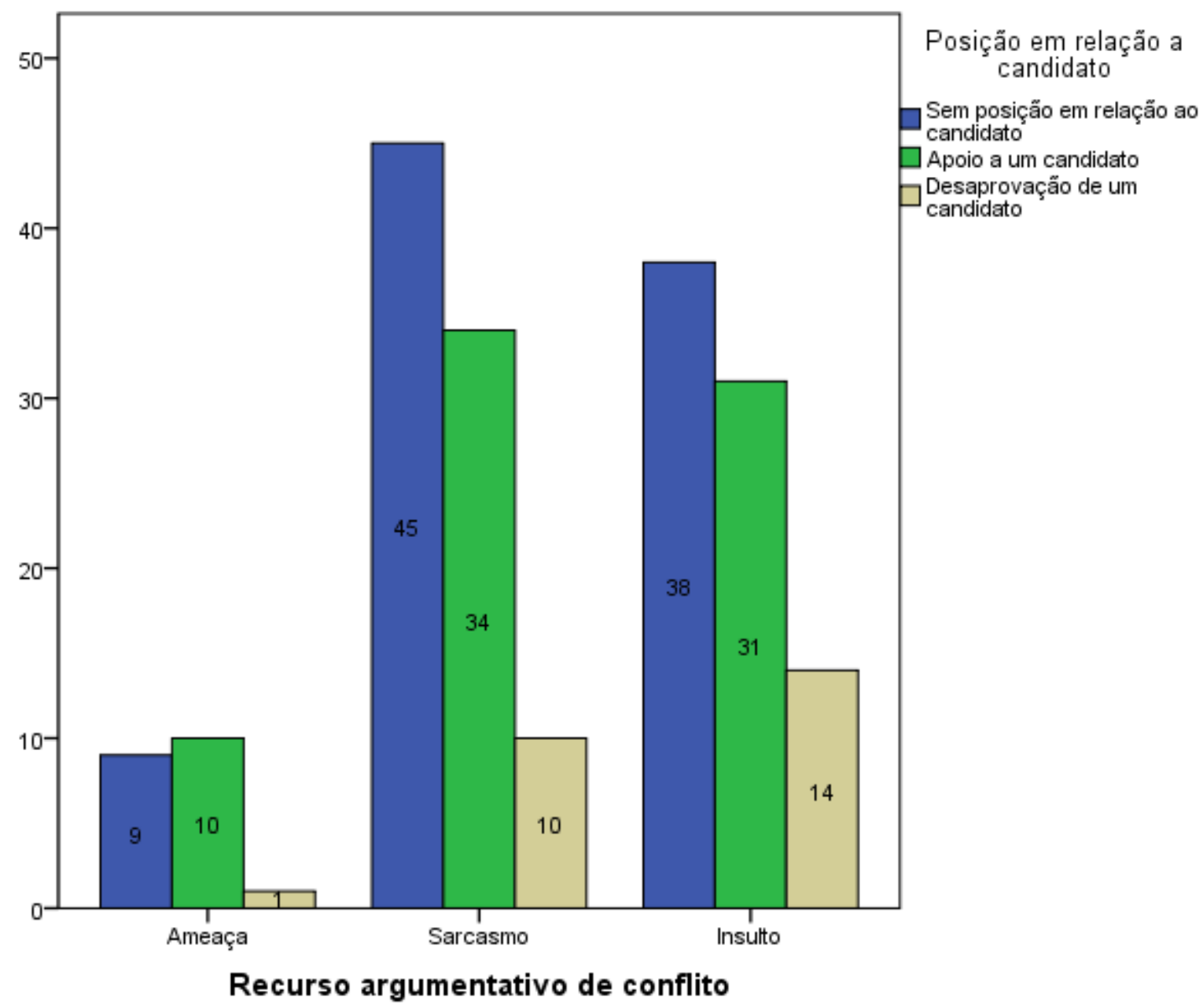

Fonte: Autores

\section{Considerações finais}


Este artigo teve por objetivo analisar como eram enunciados os pontos de tensão entre as conversas dos internautas brasileiros sobre política durante a cobertura eleitoral brasileira em 2018. O foco de atenção esteve centrado no cruzamento das variáveis com a relação de apoio e desaprovação dos candidatos. O resultado nos mostrou que nossa H1 estava correta, enquanto a H2 estava refutada, porém nos oferecendo pistas sobre o comportamento dos eleitores dentro dos espaços discursivos disponibilizados pela fanpage do jornal Estado de S. Paulo.

Discutimos que a s redes sociais e a internet alteraram as formas de interação entre as pessoas, desencadeando efeitos diversos que refletem na política e em outras instâncias sociais. De um modo geral, observamos o impacto do digital nas formas de engajamento político da atualidade, manifestando características distintas daquelas observadas no período anterior à era da conexão móvel, o que suscitou um arcabouço teórico e empírico próprio (e que está em construção) na comunicação e na política. Esse embasamento reforçou, precisamente, a importância do uso das conversas informais da internet como objetos capazes de oferecer reflexões importantes para o campo da comunicação política.

Ressaltamos, também, o papel que os afetos e as paixões exercem sobre a política, principalmente nos espaços não institucionalizados. Isso porque são nessas arenas que a crônica cotidiana passou a incorporar questões políticas de interesse comum. A tarefa desta pesquisa, trabalhando a análise em função da teoria, foi também a de fazer uma reflexão sobre as maneiras pelas quais os eleitores e as conversas políticas mudaram - e mudam em aparência e funcionalidade em reação à presença do Facebook.

Já não é mais novidade, portanto, que das múltiplas relações que nascem nesses espaços relativamente autônomos, agregam-se amplos grupos e identidades dotados das mais distintas vozes possíveis. Estes, por sua vez, veem nos canais de circulação virtual um potencial inesgotável de propagação e de registro de suas posições ante as questões públicas. A popularização da internet não significou, no entanto, como se esperava nos primeiros trabalhos acadêmicos, grandes efeitos cívicos e democráticos. As ferramentas se destinam a diversas funcionalidades, mas seus usos e, sobretudo, os atos discursos narrativos nelas registrados demonstraram agressividade, sentimento de intolerância e pouca interação entre os sujeitos. Estas características podem ser encaradas como animosidades, barreiras que dificultam a avaliação da qualidade discursiva dessas arenas enquanto esferas públicas. 
A circulação e o engajamento dos usuários contidos na plataforma do Facebook, em especial, o uso do espaço dos comentários, se configuram hoje como uma das principais formas de manifestação de opinião no que diz respeito à política e outras questões comuns da atualidade. Tais práticas reconfiguram os usos dessas plataformas e são importantes instrumentos para a avaliação dos seus efeitos nas práticas de sociabilidade. Se boa parte de nossas atividades e diálogos estão registradas em um site de rede social, também parece razoável a ideia de que os sinais dessa interatividade ecoem na vida política e democrática. Em consonância com a dinâmica do suporte do Facebook, graças aos tipos de engajamento dos conteúdos, é reconhecível que existe um potencial de circulação de informação na web que chega a ser viral em determinados momentos. Sobre isso, as fartas notícias sobre escândalos de fake news durante períodos eleitorais e até mesmo as movimentações políticas ocorridas nos últimos anos são tipos que não nos deixam mentir.

\section{Referências Bibliográficas}

ALBUQUERQUE, A. A Comunicação Política depois do Golpe: notas para uma agenda de pesquisa. Compolítica, n. 8,. 2, 2018, p. 171-206. Disponível em: <<https://doi.org/https:// doi.org/10.21878/compolitica.2018.8.2.193>. Acesso em: 12/08/19

ALDÉ, Alessandra; ESCOBAR, Juliana; CHAGAS, Viktor. A febre dos blogs de política. Famecos, Porto Alegre, v. 33, p.29-40, ago. 2017.

AMOSSY, Ruth. Apologia da Polêmica. São Paulo.Editora Contexto, 2011.

BARROS, S., \& Carreiro, R. (2015). A discussão pública e as redes sociais online: os comentários de notícias no Facebook. Revista Fronteiras - estudos midiáticos, 17(2), pp. 175-185. En: http://revistas.unisinos.br/ index.php/fronteiras/article/view/fem.2015.172.05

BRUGNAGO, Fabrício; CHAIA, Vera. A nova polarização política nas eleições de 2014: radicalização ideológica da direita no mundo contemporâneo do Facebook. Aurora: revista de arte, mídia e política, São Paulo, v. 7, n. 21, p.99-129, jan. 2015.

CASTELLS, Manuel. A sociedade em rede. São Paulo: Paz \& Terra, 2009.

CLETO, Murilo Prado; CORRÊA, Murilo Duarte Costa. A hipótese bolsonarista: as trincheiras e as linhas. Lugar Comum, Rio de Janeiro, n. 54, p.266-290, jul. 2019. Disponível em: $<$ http://uninomade.net/wpcontent/files_mf/1564694757Revista\%20Lugar\%20Comum\%20n.\%C2\%BA\%2054.pdf>. Acesso em: 20 ago. 2019.

DELEUZE, Gilles, GUATTARI, Felix. Mil Platôs. Editora 34. São Paulo, 2011.

NETO, fausto, A. (2008). Fragmentos de uma «analítica» da midiatização. MATRIZes, 1(2), 89105. 
FREIRE, Fernanda Alcântara. Eleições da Zueira: Memes, humor e política nas eleições presidenciais de 2014.155 f. Dissertação (Mestrado) - Curso de Comunicação Social, Universidade do Estado do Rio de Janeiro, Rio de Janeiro, 2016.

GOMES, Wilson. A democracia digital e o problema da participação civil na decisão política. Revista Fronteiras, São Leopoldo, n.3, 2005.

GOMES, Gilberto. Midiatização: um conceito, múltiplas vozes. Famecos, Porto Alegre, 2016.

HABERMAS, Jürgen. Mudança estrutural da esfera pública. São Paulo: Editora Unesp, 2014.

JENKINS, Henry. Cultura da Convergência. São Paulo: Aleph, 2015.

LATTMAN-WELTMAN, F. (2015). "Democracia e revolução tecnológica em tempos de cólera: influência política midiática e radicalização militante". Anais do VI Congresso da Compolítica, Brasil, Rio de Janeiro

MASSUCHIN, Michele Goulart; CERVI, Emerson Urizzi. Tipos de engajamento e circulação de notícias nas redes sociais: A relação da audiência com os temas publicados nas fanpages de jornais regionais brasileiros. Eptic, São Cristóvão, v. 20, n. 3, p.193-214, set./dez. 2018.

MASSUCHIN, Michele Goulart; MITOZO, Isabele Batista; CARVALHO, Fernanda Cavassana de. Eleições e debate político on-line em 2014: os comentários no Facebook do jornal O Estado de S. Paulo. Revista Brasileira de Ciência Política, Brasília, n. 23, p.295-320, maio/ago. 2017.

MENDONÇA, Ricardo Fabrino; SAMPAIO, Rafael Cardoso; SAMPAIO, Samuel Anderson Rocha. Deliberação Online no Brasil entre iniciativas de democracia digital e redes sociais de conversação.Belo Horizonte: E-livros (edufba), 2016. Disponível em: <https://repositorio.ufba.br/ri/handle/ri/19267>. Acesso em: 12 set. 2019.

MENEZES, Renato Contente Freire de. Entre a anormalidade e a abjeção dos corpos: egularidades temáticas do discurso LGBTfóbico nos comentários da página do Facebook do Diário de Pernambuco. 151 f. Dissertação (Mestrado) - Curso de Comunicação Social, Universidade Federal de Pernambuco, Recife, 2018.

MODESTO, Michelle. Propaganda política e discursos de verdade nas redes sociaiscolaborativas: as eleições de 2016. Rio de Janeiro, 2017. Dissertação (Mestrado emComunicação e Cultura) - Escola de Comunicação, Universidade Federal do Rio de Janeiro,Rio de Janeiro, 2017.

MOUFFE, Chantal. Sobre o político. Tradução de: Fernando Santos. São Paulo: Martins Fontes, 2015.

ORTELLADO, Pablo. Los brasileños leen Facebook: Izquierdas y cultura política digital. Nueva Sociedad: democracia y política en América Latina, Buenos Aires, n. 269, p.127-136, jun. 2017.

RECUERO, Raquel. Atos de Ameaça a Face e a Conversação em Redes Sociais na Internet.n: Alex Primo. (Org.). Interações em Rede. 1ed.Porto Alegre: Sulina, 2013, v. 1, p. 51-70

REIS, R., ZANETTI, D. e Frizzera, L. A conveniência dos algoritmos, Compolítica, 10(1), p. 35$58,2020$. 
RÜDIGER, Francisco. (2011). As teorias da comunicação. Porto Alegre: Penso. 152 p

SAMPAIO, Rafael Cardoso; BRAGATTO, Rachel Callai; NICOLÁS, Maria Alejandra. A construção do campo de internet e política: análise dos artigos brasileiros apresentados entre 2000 e 2014. Revista Brasileira de Ciência Política, Brasília, v. 20, n. 1, p.285-320, dez. 2016.

SANTOS, Matheus Lock. Comunicações transversais: cruzamentos e confrontos de opiniões nas redes digitais sobre o preconceito pós-eleitoral. 2012. 196 f. Dissertação (Mestrado) - Curso de Comunicação e Informação, Universidade Federal do Rio Grande do Sul, Porto Alegre, 2012.

SILVEIRA, Sergio Amadeu da. Direita nas redes sociais online. In: CRUZ, Sebastião Velasco e; KAYSEL, André; CODAS, Gustavo. Direita, Volver!: O retorno da direita e o ciclo político brasileiro. São Paulo: Fundação Perseu Abramo, 2015. p. 213-230

SINDERSKI, Rafaela, CERVI, Emerson. Conversação Política na Fanpage do Movimento Brasil livre: uma análise das discussões sobre a redução da maioridade penal entre 2015 e 2018 . Teoria e Pesquisa, v.28, n.3, 2019.

TARDE, Gabriel. A opinião e as Massas. São Paulo: Martins Fontes, 2005.

TEIXEIRA, Antonio Claudio Engelke Menezes. As paixões, os interesses e a Internet. Perspectivas, Revista de Ciências Sociais, São Paulo, n. 40, p.201-221, dez. 2011.

VAN DIJCK, José. La cultura de la conectividad. Buenos Aires: Siglo Veintiuno Editores, 2016. 